\title{
TRANSFORMACIONES EN LA IDENTIDAD FEMENINA, CAMBIO GENERACIONAL Y REVOLUCIÓN: PRIMERA MITAD DEL SIGLO XX
}

\author{
TRANSFORMATIONS IN FEMALE IDENTITY, \\ GENERATIONAL CHANGE AND REVOLUTION: \\ FIRST HALF OF THE 2OTH CENTURY
}

\author{
Rosario Margarita Vasquez Montaño \\ (iD) orcid.org/0000-0002-5605-7749 \\ El Colegio Mexiquense, A.C. \\ México \\ rvasquez@cmq.edu.mx
}

\begin{abstract}
This article aims to identify and analyze the generational changes experienced by women in public and private spaces, in the context of the feminism as a political and ideological movement that sought equal rights and conditions for women during the first decades of the Twentieth Century. Through the biography of the American socialist writer Ethel Duffy Turner, I identify different areas of transformation that we can link with the female emancipation. Through the analysis of Newspapers, magazines, memoirs, historical and historiographic contextualization, elements are proposed that allow identifying the profile and conformation of modern women and their characteristics.
\end{abstract}

Keywords: bohemian, California, feminism, gender, women.

\begin{abstract}
Resumen
Este artículo identifica y analiza los cambios generacionales que experimentaron las mujeres en su relación con el espacio público y privado en el contexto del posicionamiento del feminismo como un movimiento político e ideológico durante las primeras décadas del siglo XX. A través de la trayectoria de la escritora socialista estadounidense Ethel Duffy Turner, identificamos diferentes ámbitos de transformación que podemos enmarcar dentro del movimiento de emancipación femenina. Mediante el análisis de hemerografía, memorias y a partir de una contextualización histórica e historiográfica, se proponen elementos que permitan identificar el perfil y conformación de las mujeres modernas y sus características.
\end{abstract}

Palabras clave: bohemia, California, feminismo, género, mujeres. 


\section{Introducción}

Al estudiar la historia de las mujeres de la primera mitad del siglo XX, es importante destacar y reconocer un proceso de transformación en torno a los ideales femeninos que se habían consolidado y sostenido a lo largo del siglo XIX, en el marco de la conformación del liberalismo y con éste, la separación de lo femenino y lo masculino en las esferas de lo privado y lo público respectivamente. A finales de ese siglo, el movimiento de mujeres se desarrolló en medio de conflictos de clase, el advenimiento de los socialismos y las revoluciones modernas. Estos factores histórico-contextuales dieron paso a un cuestionamiento por parte de las mujeres sobre el lugar que ocupaban en la sociedad. La lucha por el sufragio por parte del movimiento feminista sólo fue uno de los diferentes tópicos del activismo femenino de la época. ${ }^{1}$ Las generaciones que nacieron durante el cambio de siglo experimentaron en carne propia los cambios producto de alteraciones en la condición de la mujer: la reforma de la vestimenta, la cultura del consumo que transformó las ciudades, la incorporación a la educación profesional universitaria, la apertura de espacios periodísticos para un público femenino cada vez mayor, el surgimiento de organizaciones femeninas de todo tipo y el involucramiento en el activismo político de diferente cuño ideológico, etcétera.

Este artículo tiene como objetivo identificar los cambios generacionales que experimentaron las mujeres en su relación con el espacio público y privado en el contexto del posicionamiento de los feminismos en busca de igualdad de derechos y condiciones para las mujeres. La biografía, como método para acercarnos a diferentes procesos históricos, se vuelve una herramienta eficaz para detectar este tipo de cambios sociales

1 Al hacer referencia al feminismo, lo hacemos en el entendido de que fue y es un movimiento plural, con una diversidad de consignas y objetivos que están relacionados con las interconexiones de las mujeres activistas en otras luchas de la época. Asimismo, en este texto se entiende el feminismo como una forma de transformación individual y colectiva de las mujeres en los diferentes ámbitos de la vida privada y pública. y culturales vinculados a la larga duración, en donde podemos reconocer un viraje en la identidad de las mujeres y en su presencia activa en la sociedad de su tiempo desde nuevas prácticas, actividades, en la relación con su cuerpo y concepciones de la maternidad, el matrimonio y las prioridades profesionales y públicas. El ensayo aborda la biografía de la escritora socialista Ethel Duffy Turner, mujer que nació en el cambio de siglo, en 1885, y fue tocada y beneficiada por la lucha de una generación anterior que abogó por el acceso a la educación y al trabajo remunerado; procuró una habitación propia para desarrollarse intelectualmente; y se involucró en el contexto político y revolucionario de su tiempo. ${ }^{2}$

El artículo está dividido de la siguiente manera: se presenta un breve acercamiento biográfico sobre Ethel Duffy Turner, para luego dar paso al análisis, a través de aspectos de su vida (cuestiones simbólicas como la vestimenta, llegada a la universidad, el papel que jugó como activista política en el movimiento socialista, su trabajo intelectual y de producción literaria) que nos permitan identificar elementos particulares que remitan a una serie de nuevas experiencias, prácticas y formas de feminidad que caracterizaron a las mujeres modernas de las primeras décadas del siglo XX. ${ }^{3}$

La historiografía sobre el movimiento de mujeres, tanto en México como en Estados Unidos, se ha desarrollado profusamente. ${ }^{4}$

2 Las reflexiones aquí presentadas provienen de una amplia investigación que he desarrollado sobre la trayectoria de Ethel Duffy Turner (Vasquez, 2019).

3 Las chicas modernas (Modern Girls) es una categoría analítica, aunque también una representación histórica, que nos permite identificar a las mujeres que se incorporaron a los espacios urbanos desde el trabajo, el arte creativo, la educación y la profesionalización, activas políticamente, pero también reproductoras de ideales de la feminidad ligados a una cultura del consumo (Weinbaum et al., 2008: 12). Mujeres que experimentaron y arroparon las transformaciones que trajo el cambio de siglo en el marco de la modernidad y el impulso modernizante de la industrialización capitalista. Asimismo, desde esta perspectiva de análisis, se considera la experiencia y representaciones de las mujeres modernas desde lo global, en el entendido de que hay diferencias en la idea y práctica de la mujer moderna, a partir del contexto nacional estudiado (Weinbaum, et al., 2008).

4 Tomo en cuenta estas dos historiografías por el ca- 
El análisis de las primeras décadas del siglo $X X$ ha sido una preocupación constante entre estudiosas y estudiosos de la historia de las mujeres y de género. El abordaje de las transformaciones que se generaron durante este periodo ha sido analizado desde la historia del consumo al develar la reconfiguración, por ejemplo, de los espacios públicos urbanos debido al surgimiento de tiendas departamentales y salones de té, así como restaurantes para mujeres (Sewell, 2011); lo mismo ocurre con las investigaciones sobre los cambios en los patrones de la vestimenta y la moda femenina, acompañados de un fuerte movimiento de reforma durante las últimas décadas del siglo XIX (Riegel, 1963; Shaffer, 1976). Asimismo, la historia del trabajo ha aportado conocimiento sustancial para identificar, por un lado, la presencia de las mujeres en el mundo obrero campesino (Hernández, 2021; Fowler-Salamini, 2013; Ramos Escandón, 2004; Chassen-López, 1994; Fernández-Aceves, 2003) y, por el otro, los nuevos espacios y puestos de trabajo a los que se incorporaron las mujeres en el contexto de la revolución industrial que no sólo engrosaron las filas de la clase obrera femenina, sino también la de la clase media en el sector de servicios profesionales (Porter, 2020). La historia del sufragismo es sin duda de gran calado, por lo que representa en la propia historia del feminismo hasta nuestros días. Lo interesante es que los estudios al respecto han complejizado el proceso histórico reconociendo vínculos entre el movimiento de mujeres, el socialismo y el anarquismo, en el caso de Estados Unidos (Katz, 1991; Hernández, 2021), y la inexorable relación entre las actoras del sufragismo mexicano y su participación en el movimiento revolucionario (Oikión Solano, 2018; Fernández-Aceves, 2014; Rocha Islas, 2011; Lau Jaiven, 2011; Tuñón Pablos, 2011; Valles Ruiz, 2010; Cano, 2007, 2006, 1996, 1993 y 1991).

Estas experiencias y procesos históricos estudiados por la historiografía son deter-

rácter transfronterizo de Ethel Duffy Turner; su producción y actividad política e intelectual estuvo relacionada con ambos espacios nacionales. minantes para explicar las transformaciones que va a traer consigo la llegada del siglo $X X$. En especial, en lo que tiene que ver con la identidad de género de las mujeres y cómo va a trascender varias generaciones que encontrarán espacios de desenvolvimiento social, personal e intelectual que, con anterioridad, no habrían conseguido, ya sea por su condición de clase o simplemente por las ataduras que representaba el mito de las esferas separadas y las ideas victorianas sobre el lugar de las mujeres en el entramado social y político de los países occidentales.

Desde finales del siglo XIX y hasta la década de 1920 las mujeres impulsaron diversas estrategias para alcanzar derechos no sólo en lo concerniente al sufragio, sino también en la consolidación de un Estado benefactor que desarrollara programas en favor de la mujer y la niñez. Koven y Michel apuntan que este proceso incidió en la consolidación de espacios laborales para las mujeres en los ámbitos del trabajo social, la enfermería, la puericultura, etcétera (Koven y Michel, 1993: 4). La maternidad y sus significados fueron llevados del espacio privado a la agenda pública por parte de mujeres reformistas organizadas (Koven y Michel, 1993: 2).

Por otro lado, entre las décadas de 1880 y 1920, tanto en Europa como en Estados Unidos, podemos reconocer tres generaciones que consolidaron "nuevas formas de la feminidad" con amplias "demandas de emancipación elaboradas por incontables asociaciones, ligas, círculos, clubes, etcétera". Esas nuevas formas de la feminidad eran evidentes "en la apariencia, los gestos y las formas de vida [y en] la firme resolución de la autonomía personal. Ninguna vez se había reclamado con tanta fuerza el derecho a desarrollar una personalidad propia" (Expósito García, 2016: 75).

Estamos ante el ejercicio de una nueva cultura femenina en donde las mujeres se encuentran entre sí, llevan a cabo prácticas de solidaridad en la organización sindical, en la creación de clubes, al hacer suyas las calles por medio del transporte, el consu- 
mo, el trabajo y el activismo político. La biografía de Ethel Duffy Turner encarna estas expresiones de las mujeres modernas, que enuncian en sus actitudes y prácticas cotidianas una nueva forma de plantarse en la sociedad frente a una reconversión en la lista de sus prioridades y proyectos de vida.

\section{Ethel Duffy Turner: una vida en la frontera}

La vida de Ethel Duffy Turner está marcada por su condición transfronteriza. Es mayormente conocida por ser una de las colaboradoras más cercanas al grupo de exiliados mexicanos miembros del Partido Liberal Mexicano (PLM) en California. Su relación de pareja con el periodista John Kenneth Turner marcó en definitiva el derrotero de su vida vinculada a la Revolución mexicana. Ethel Evelyn Duffy Palmer nació en 1885, creció en el cambio de siglo en una familia de clase media que residía en la colonia de trabajadores de la prisión de San Quintín, su padre era guardia. Estudió la preparatoria en San Rafael y después ingresó a la Universidad de California, en Berkeley, para estudiar la carrera de Literatura inglesa en 1902 (Duffy Turner, 1967: 5).

Durante su etapa universitaria Ethel conoció al joven socialista y periodista John Kenneth Turner, con quien se casó en 1905 (Duffy Turner, 1967: 8). El matrimonio la llevó a abandonar sus estudios a poco de graduarse. Los intereses políticos y profesionales de Turner, así como la devastación provocada por el terremoto de 1906 en la Bahía de San Francisco, hicieron que la pareja se trasladara a Los Ángeles en 1907. Las redes con las que contaba Turner facilitaron la adaptación a la ciudad y al dinamismo político que en ese entonces ocurría debido al activismo de los movimientos obrero, socialista y sufragista. Además, Los Ángeles, por su cercanía con México y por contar con una importante comunidad de origen mexicano, era centro de recepción de exiliados políticos que huían de la persecución del gobierno de Porfirio Díaz.
En Los Ángeles se encontraba la Junta Organizadora del Partido Liberal Mexicano. Entre sus miembros estaban los hermanos Ricardo y Enrique Flores Magón, Antonio I. Villarreal, Librado Rivera y Práxedis Guerrero. Cuando los Turner llegaron a la ciudad, se encontraban detenidos algunos de estos personajes. John Kenneth se enteró de la detención, considerada injusta por los socialistas, y decidió acudir a la cárcel y entrevistarlos. A partir de ese momento, se conformó un grupo de socialistas que dedicaría tiempo, dinero y esfuerzo para trabajar en la liberación de los presos y posteriormente coadyuvar en la lucha revolucionaria del PLM en México. Entre estos personajes se encontraban el abogado y líder socialista Job Harriman, la sufragista Frances Noel y su esposo P.D., la joven Elizabeth Trowbridge, el dirigente obrero John Murray, así como John Kenneth Turner y Ethel Duffy.

En esta etapa de colaboración estrecha con la Junta Organizadora del PLM, Ethel Duffy poco a poco se adentraría en el mundo del activismo resultándole atractivo. Junto a Trowbridge, respondía correspondencia y realizaba trabajo de oficina; asimismo se dedicó a ofrecer clases nocturnas gratuitas de inglés a obreros (Duffy Turner, 2003: 172). Su compromiso con la causa de la revolución en México tuvo su más álgida expresión cuando editó la revista cultural The Border, por un periodo muy corto entre 1908 y 1909, y al convertirse en la editora de la página en inglés de Regeneración, órgano oficial del PLM, durante 1911, año crucial para la Junta por su incursión y toma del territorio de Baja California. ${ }^{5}$ El trabajo editorial de Ethel Duffy Turner no sólo estuvo

5 La revista The Border fue editada en Tucson, Arizona, entre 1908 y 1909, en el marco de la encarcelación de varios miembros de la Junta Organizadora del PLM en ese estado. La revista tenía como objetivo promover la liberación de los presos. Se autodefinía como "una revista mensual de política, noticias e historias de la frontera". Debido al espionaje y la persecución, la revista sólo logró sacar a la luz 3 números. Por su parte, Regeneración, órgano oficial del PLM desde 1905, tiene sus orígenes en México en 1900. La sección en inglés del periódico se añadió a partir de su cuarta época, en 1910. Según Armando Bartra, Enrique Flores Magón llegó a hablar de alrededor de 30 mil suscriptores (Bartra, 1980: 59). 
relacionado con la traducción de textos de los dirigentes, escribió y publicó artículos de opinión en torno a temas del momento, siempre dirigiéndose a sus compatriotas lectores con críticas al imperialismo e intervencionismo de su país, y de cuestionamiento al nacionalismo estadounidense y las posturas contrarias a la Revolución mexicana (Duffy Turner, 1910a, 1910b, 1911a, 1911b, 1911c).

Pero 1911 también fue el año del triunfo de la revolución dirigida por Francisco I. Madero y eso representó rompimientos al interior de la Junta y del grupo compacto de socialistas estadounidenses que se solidarizaron con su causa. John Kenneth Turner anunció ante la prensa de su país, después de haber contrabandeado armas en la frontera, que se retiraba de cualquier actividad relacionada con el periodismo de guerra para dedicarse a cuestiones más pacíficas (Shoaf, 1911). Unas semanas atrás, Ethel había dejado su trabajo como editora de Regeneración, para ser sustituida por el anarquista inglés William C. Owen. El viraje de la Junta hacia el anarco comunismo se había completado con la publicación del Manifiesto del 23 de septiembre de ese año.

El rompimiento fue muy significativo para Ethel en un primer momento, sobre todo porque no fue una decisión propia. No obstante, su vida se vio empapada con una revolución cultural y artística gracias a su llegada a la bohemia de Carmel By the Sea, en California, fundada por el poeta George Sterling y la escritora Mary Austin a inicios de siglo. En ese lugar Ethel comenzó a escribir sus primeros trabajos poéticos, se adentró en el mundo de la pintura y en el teatro al aire libre. La estancia en ese lugar se alargó hasta 1917, cuando devino su divorcio. Junto a su hija Juanita (1909-1974) se mudó a San Francisco. Las redes que había tejido durante su tiempo en Carmel le permitieron conectarse con artistas, escritores y editores que hicieron posible que desarrollara su carrera literaria. En las décadas de 1920 y 1930, Ethel Duffy Turner llegó a publicar para periódicos y revistas. En 1934 salió a la luz su novela One-Way Tic- ket, considerada de corte autobiográfico, la cual fue llevada al cine un año después. Durante este tiempo, y gracias a las regalías recibidas por la venta de los derechos de su libro, realizó varios viajes a Europa, con la intención de conectarse con sus orígenes irlandeses que le permitieran inspirarse para futuras ideas literarias. Se comprometió en las actividades realizadas por el Frente Popular en California contra el fascismo; colaboró en la recaudación de fondos de apoyo para las brigadas militares que acudieron en defensa de la república española y escribió para la revista New Masses en el contexto del posicionamiento del nazismo en Europa y sus efectos en Estados Unidos.

El reencuentro de Ethel Duffy Turner con México se dio en la década de 1940, cuando tuvo contacto con antiguos miembros del Partido Liberal Mexicano, como Blas Lara y Fernando Palomares, quienes permanecieron en California después del desvanecimiento de la Junta y el PLM. Estos personajes la conectaron con otros veteranos de la revolución en México, como Nicolás T. Bernal, Jesús Rangel y José María Leyva. Gracias a estas conexiones y su incorporación a los debates historiográficos en torno al papel del llamado "magonismo" en la historia de la revolución, la escritora decidió asentarse en México en 1955, luego de recibir una invitación por parte del expresidente Lázaro Cárdenas para que escribiera una biografía sobre Ricardo Flores Magón bajo su tutela y financiamiento. En 1960 se publicó su libro más conocido y referenciado hasta hoy en día, Ricardo Flores Magón y el Partido Liberal Mexicano. Es paradójico que haya llegado a México un año después que las mujeres mexicanas obtuvieron el derecho al voto, experiencia que en su país había ocurrido, a nivel federal, en 1920.

Durante la década de 1960 Ethel Duffy Turner decidió radicar en Cuernavaca, Morelos. En ese lugar conectó con sus compatriotas exiliados del macartismo; continuó escribiendo y publicando sobre la historia del PLM en la prensa nacional. Su conexión con California no la perdió. Durante sus viajes a su tierra natal continuaba promovien- 
do su obra entre las editoriales, su poesía en revistas y periódicos, al tiempo que acudía a las concentraciones y movilizaciones estudiantiles de la bahía de San Francisco contra la guerra en Vietnam, la lucha por los derechos civiles y el Free Speech Movement en la Universidad de California, en Berkeley.

Los últimos años de vida de la californiana estuvieron marcados por el constante deseo de seguir escribiendo, aun y a pesar de una situación de salud precaria. Sus condiciones de vida fueron denunciadas en la prensa nacional: una mujer que había sido descobijada por el Estado mexicano, en su calidad de veterana revolucionaria. Atendida por una enfermera estadounidense que había sido parte de la Brigada Lincoln durante la guerra civil española, Ethel murió en agosto de 1969.

\section{Modernidad y género. Nuevos escenarios, prácticas y símbolos de feminidades alternas}

\section{Educación, profesionalización, trabajo remunerado y cultura escrita}

Uno de los aspectos que las historiadoras señalan como nodales para explicar las transformaciones en la identidad femenina durante el cambio de siglo es el del acceso a la educación y la conformación de una cultura escrita, otorgándole a las mujeres la posibilidad de reconfigurar visiones del mundo, la sociedad y su lugar en ella. Ethel Duffy Turner formó parte de una generación de jóvenes entusiastas de clase media que logró incursionar en la Universidad de California, en Berkeley.

La incorporación femenina a esta institución educativa, fundada en 1868, fue un proceso paulatino en el que intervinieron las propias mujeres en busca de ser admitidas. Cuando Ethel ingresó en 1902, de un total de 2456 estudiantes, 1063 eran mujeres (University of California, 1898: 389), la mayoría en carreras ligadas a las humanidades y las ciencias sociales. La feminización de este tipo de carreras fue un fenómeno que ocurrió en diferentes espacios educativos. Por ejemplo, en 1898, en el Colegio de Letras de la Universidad de California había inscritos 91 hombres y 104 mujeres y en Ciencias Sociales 299 y 452, respectivamente. Para 1903 había matriculadas 172 mujeres y 107 varones en Letras; en Sociales el número era de 695 mujeres frente a 257 hombres (University of California, 1898: 389; University of California, 1903: 535).

La educación ofrecida para las jóvenes como Ethel estaba sustentada "en las mejores líneas de una cultura liberal, incluyendo idioma, literatura, historia y ciencias políticas", lo que daba la oportunidad para que las estudiantes realizaran "estudios literarios, lingüísticos, históricos y económicos, así como la preparación para las escuelas profesionales" (University of California, 1903: 103).

El acceso a un conocimiento profundo y racional sobre los pensadores del mundo antiguo y moderno (University of California, 1903: 182-190) explican la formación de una cultura escrita que es leída, discutida y retomada por las mujeres durante sus estudios universitarios, pero también en su vida profesional como escritoras en el ámbito del periodismo, la producción literaria y los trabajos como empleadas en oficinas.

En su novela autobiográfica One-Way Ticket, Ethel se refirió a su etapa universitaria. Resaltó la forma en la que eran recibidas las estudiantes, a quienes se les prometía alejarlas de la literatura romántica estereotipadamente dirigida a mujeres:

\footnotetext{
"We have put certain reading on the required list", said the English Department, "in an attempt to break down your prejudices. The books we have selected are not pleasant romances; but remember, this is a university, not a ladies" seminary [...] (Duffy Turner, 1934: 315).
}

La universidad era un espacio vigoroso y masculino y, por lo tanto, las jóvenes debían adaptarse a lo que se ofrecía y dejar atrás ideas preconcebidas de lo que significaba la literatura que, se asumía, hasta ese entonces habían leído. Incluso Ethel identificó 
las diferencias y limitaciones que ella, y las mujeres que se adentraban en el mundo de la literatura de la mano de la universidad, tenían frente a hombres con autoridad que

talked smoothly of breaking down prejudices, these beautifully cultured young Ph.D's with the brave minds, the faultless personal behavior, the Harvard, if not the Oxford, accent. Their lives were shaped to a gentle routine; it was not difficult for them to follow a clean trail through books to an easy charming freedom (Duffy Turner, 1934: 315).

El éxito en los estudios dependía no sólo de la intención de las jóvenes, sino además de la apertura institucional y de recursos económicos que les permitieran cambiar de residencia o trasladarse diariamente a la universidad desde diferentes puntos de la Bahía de San Francisco. Las becas se volvieron un factor sustancial. Ethel se vio beneficiada con una de ellas, con la cual pudo seguir viviendo en la casa paterna en San Quintín y viajar a diario en ferry a Berkeley (Duffy Turner, 1967: 5). El papel que jugaron mujeres de la élite al respecto es significativo. Por ejemplo, Phoebe Apperson Hearst (1842-1919), madre del magnate del periodismo William Randolph Hearts, fue mecenas del mundo universitario y en particular en el apoyo a las mujeres para su desarrollo profesional, tal es el caso de la "Phoebe A. Hearst Scholarships for Women" (University of California, 1903: 99). También utilizó su fortuna en la creación de guarderías para las mujeres trabajadoras de San Francisco. Estos factores y su condición de clase le permitieron convertirse en la primera mujer regente de la Universidad de California (Jensen y Ricci, 1987: 46; Anónimo, 1905).

La universidad era la primera etapa para la formación de criterios propios y una cultura escrita, la cual permitió a las mujeres incorporarse al trabajo remunerado gracias a sus habilidades como redactoras, transcriptoras y escritoras con conocimiento literario o de tipo social. Esto se debía a un cambio en las percepciones que éstas tenían de su rol en la sociedad de su tiempo. La histo- riografía estadounidense ha destacado el surgimiento de un arquetipo de una Nueva Mujer que se posicionaría entre las jóvenes a inicios del siglo XX. Mujeres modernas y entusiastas que habían desestimado los roles tradicionales al reconfigurar la sexualidad femenina, que hacían uso del derecho a la educación superior y al ejercicio profesional y laboral (Showalter, 2009: 210). ${ }^{6}$

Lo que se conocía como el espacio público se transformó desde el momento que las mujeres hicieron acto de presencia de variadas formas y desde diferentes estratos socioeconómicos. Las mujeres de clase alta como Apperson Hearst usaron sus recursos para favorecer el sufragio, así como para actos de beneficencia y caridad. Por su parte, un importante número de mujeres de clase media, que habían tenido la oportunidad de salir de sus localidades para estudiar en las universidades, se trasladaron a centros urbanos para trabajar y al mismo tiempo incorporarse a diferentes organizaciones femeninas y feministas. Por su parte, las obreras se organizaron para mejorar las condiciones de trabajo en igualdad de condiciones frente a sus pares masculinos.

Por ejemplo, cuando Ethel regresó a San Francisco como madre divorciada en 1917, se incorporó al mercado laboral como muchas otras mujeres de su tiempo. Comenzó trabajando como operadora de dictáfono para General Electric y realizando traducciones para una empresa minera con inversiones en México (EDT-Banc: Box 1). ${ }^{7}$ En una carta del todo cordial, John Kenneth Turner sugirió a Ethel que estableciera contacto con el poeta George Sterling, con quien ha-

\footnotetext{
6 Aunque existen diferencias entre el arquetipo de la Nueva Mujer y el de la Mujer moderna, debido a que estamos ante al menos dos generaciones de mujeres, a intereses y actividades social y políticamente diferenciadas (reformistas frente a socialistas y feministas revolucionarias); es evidente que hay una yuxtaposición entre ambos arquetipos debido a que uno alimentó al otro. Por ejemplo, los cambios en la reconfiguración de los cuerpos de las mujeres y la confección de indumentaria acorde a los aires de libertad promovidos por la flapper no se pueden entender sin los antecedentes de la reforma de la vestimenta de finales del siglo XIX.

7 Ethel Duffy Turner a John Kenneth Turner; San Francisco, California, 2 de diciembre de 1919.
} 
bían construido una relación de amistad en la bohemia de Carmel años atrás. Las redes eran de suma importancia para lograr construir una carrera en el mundo de las letras. Antes de recurrir a Sterling, Ethel decidió enviar un poema al afamado editor y periodista de denuncia Fremont Older, quien dirigía el San Francisco Call. Era conocido por ser un editor que creía fervientemente en el trabajo periodístico de las mujeres por su diligencia y responsabilidad; incluso creía que el enemigo en la carrera de las periodistas era el amor, el cual terminaba por arruinarlas (Ross, 1936: 580). Older vio con buenos ojos la propuesta de Duffy y le ofreció una columna para que publicara sus poemas en el periódico, de esta manera arrancó la carrera literaria de la escritora en San Francisco.

Los poemas tenían como temática la ciudad. Resulta sumamente atractivo debido a que estamos ante una creación poética que se alimenta del deambular de la autora por las calles de San Francisco.

Su valor histórico es relevante porque nos presenta los espacios que una mujer de su época recorre y con los cuales interactúa sola, acudiendo al placer de observar paisajes, personas, lugares de socialización como el cine, un café, una tienda departamental, un viaje en tranvía, etcétera. Mujeres como Ethel tuvieron la oportunidad, como en ningún otro momento de la historia, de expresar desde una particular subjetividad sus ideas y creaciones.

Cabe señalar que este fenómeno había sido impulsado desde finales del siglo XIX en California. Por ejemplo, la Pacific Coast Women's Press Association, fundada en 1890, fue una importante organización de mujeres que promovió la colaboración de periodistas, editoras y escritoras en general, para consolidar redes a lo largo de la región que permitiera preservar y ampliar el trabajo intelectual y profesional de las mujeres en el ámbito de las letras (Peaslee, 1891).

Este aspecto contribuyó a un boom en la creación de periódicos y revistas editados por y para mujeres. Showalter (2009: 210-220) destaca que es posible reconocer también la producción de nuevas formas de escritura sobre las mujeres desde la literatura y el periodismo. Para el cambio de siglo, periódicos de gran calado ya sostenían secciones dedicadas a un público de lectoras, debido a la amplitud de un mercado ávido de noticias y temas relacionados con lo femenino y las mujeres (Yamane, 2000: 193).

\section{El cuerpo y la indumentaria como formas evidentes del cambio}

En este proceso de incorporación de las mujeres a diferentes ámbitos de la vida pública desde los estudios universitarios y por ende la profesionalización que significaba la incorporación al mercado laboral, vale la pena destacar lo que representó su transitar en esos espacios. El cambio no se puede identificar como una excepcionalidad, sino que formó parte de un proceso que se acentuó a finales del siglo XIX por el desarrollo tecnológico y la modernización de vías férreas, marítimas y de transporte público que conectaron lugares periféricos con los centros urbanos. Por ejemplo, para 1900 la bahía de San Francisco contaba con una red pública de transporte que hacía posible el tránsito alrededor de ésta. (Sewell, 2011: 15). Cuando Ethel ingresó a la universidad estuvo viviendo algunos meses en Berkeley, pero gracias a una beca pudo costear el transporte público y cruzar la bahía de San Quintín, donde se encontraba la casa familiar, a San Francisco. El trayecto, que iniciaba a las cinco de la mañana, implicaba tomar un autobús, un ferri y dos trenes (Duffy Turner, 1967: 5).

Por otro lado, la ciudad de San Francisco, por su carácter de puerto y centro de negocios, se convirtió en un crisol multiétnico y cosmopolita. Debido a la modernización y a la amplitud de las prácticas y ofertas de consumo, transitó de la segregación de género a una integración de las mujeres como compradoras de las nuevas tiendas departamentales, o como trabajadoras que usaban los medios de transporte para trasladarse de sus hogares a los espacios laborales (Jensen y Ricci, 1987: 35; Sewell, 2011: $x x i i)$. 
En ese tenor también habría que destacar otros fenómenos ligados entre sí: la popularización de la bicicleta, como medio de transporte y recreación para las mujeres; y la reforma de la vestimenta de mediados del siglo XIX. Ambos fenómenos sociales impactaron en el proceso de emancipación femenina mediante el uso físico y la transformación de la imagen del cuerpo. Komski (2001) identifica dos periodos en la historia del movimiento de reforma de la vestimenta. El primer momento tiene una extensión de dos décadas (1850-1870), caracterizado por ser más radical que el segundo (18701900) (Komski, 2001: 3). Los dos tenían un objetivo común, el cambio en la moda de las mujeres en favor de la comodidad y la preservación de la salud. Pero también tenían marcadas diferencias. La etapa inicial estuvo impulsada por médicos, asociaciones religiosas, grupos de obreras y campesinas $y$, principalmente, por defensoras de los derechos de las mujeres (Komski, 2001: 3), lo que explica el ímpetu transgresor que no fue a veces bien recibido por la sociedad de la época. La segunda etapa fue más conservadora, ya que reforzaron los roles femeninos ligados a la maternidad (Komski, 2001: 4) y a la larga tendieron a no rivalizar con la industria de la moda (Komski, 2001: 5). Las reformas de la primera etapa consideraban la renovación de la vestimenta como un medio para alcanzar la igualdad de las mujeres en los diferentes ámbitos de la vida social (Komski, 2001: 3)

No obstante, es posible reconocer continuidades entre los postulados de la reforma de la vestimenta feminista de 1850-1870 y las mujeres de la generación de Duffy Turner en California. No es extraño, por lo tanto, que, en su etapa universitaria en Berkeley, Ethel se topara con el movimiento de mujeres. Mary McHenry Keith (1855-1948) pionera del sufragismo con una presencia sustancial en la región, era la presidenta de la Berkeley Political Equality Society y lideraba un club de 200 sufragistas, el más numeroso de la costa este de la bahía según Weinstein (2008: 97). McHenry, además, era conocida por estar inmiscuida en el movimiento por la reforma de la vestimenta, consciente de la importancia de "liberar a las mujeres de las modas que inhibían y obstaculizaban sus intentos de triunfar en la escuela y la universidad" (Shaffer, 1976: 477).

El caso de Ethel revela el vínculo con la reforma de la vestimenta, en particular en lo que tiene que ver no sólo con el tema de la comodidad y la practicidad al vestir, sino como un elemento que resalta el rechazo de algunas mujeres a los nuevos arquetipos femeninos que se instauraron en el contexto de la llamada Belle Époque, a finales del siglo XIX. El matrimonio de Ethel con el periodista John Kenneth Turner dejó muy pocas evidencias documentales, sólo una fotografía tomada en Fresno en 1905; en ésta destaca la figura de ella con un atuendo extremadamente sencillo, para lo que podría haber sido una fotografía de estudio nupcial fechada el 15 de marzo. Su atavío está compuesto por una camisa acompañada por una corbata oscura y el cabello completamente recogido (OAC, s.f.). El ambiente de las mujeres sufragistas de Berkeley y San Francisco habían dejado una impronta de ideas y posicionamientos políticos e ideológicos que debieron retomar las jóvenes generaciones. Aunque no hay evidencia tácita que nos haga situar a Ethel directamente en el activismo feminista, sí podemos decir que su vida estuvo influida enormemente por el movimiento amplio de mujeres desde prácticas emancipadoras que la llevaron a apropiarse de formas de presentarse en el espacio público corporalmente desde una vestimenta austera, contraria a los ideales de belleza del momento, e incluso incorporar el tema a su producción poética.

Así lo hizo en un poema cargado de ironía y crítica al arquetipo de la Gibson Girl, ideal femenino que se posicionó gracias a la aparición en diferentes revistas de tiraje nacional. Este arquetipo se consolidó gracias a las ilustraciones realizadas por Charles Dana Gibson. En estas era posible vislumbrar algunos cambios en el desenvolvimiento femenino en la sociedad (Gourley, 2008: 30 y la sofisticación y atuendos elaborados que tuvieron gran resonancia gracias a la 
propaganda y prácticas de consumo del momento (Sewell, 2011: 26). El poema "An Art-less Maid", escrito por Ethel, apareció en la revista Life en 1913; la poeta se burla de la ingenuidad de las mujeres que se dejaban seducir por el consumo y los valores que promovía y prometía la imagen de la Gibson Girl: "Dad goes in debt to robe me, yet/l'm sighing all the while/For dainty dresses and silk hose [...]" (Duffy Turner, 1913). Ethel no se sentía identificada con el ideal femenino de su época de juventud, que vendría a ser desplazado por otro fenómeno arquetípico como el de las flappers en la década de 1920.

\section{Mujeres que se mueven solas. Apropiación de espacios y cruce de fronteras}

Durante el cambio de siglo las mujeres no sólo se incorporaron a los espacios laborales y de consumo en ciudades como San Francisco. La propia profesionalización de las mujeres las llevó a lugares más allá de las ciudades que deambulaban; su incorporación a movimientos políticos le otorgó una movilidad inusitada a causa del activismo. Aunque las estadounidenses de clase alta ya habían logrado realizar viajes como el Grand Tour europeo, disputando un ritual masculino que se inauguró en Inglaterra a finales del siglo XVII (Beatty, 2016: 10), Smith apunta que durante el periodo que nos ocupa estamos ante la experiencia de una movilidad individualizadora, producto del capitalismo y la innovación tecnológica en las máquinas que al mismo tiempo transformaron espacios, tiempos y ampliaron los objetivos del viaje (Smith, 2001: XI). Es decir, aumentaron las posibilidades para periodistas, artistas, editoras y aventureras de explorar territorios desconocidos (Smith, 2001: XI) o, en su caso, experimentar con otros desde espacios de contacto como las zonas fronterizas; alterando, de esta forma, sus experiencias y con ellas las formas de "imaginar, sentir y pensar el mundo en el que viven" (Pratt, 2010: 26).

Ethel Duffy fue una mujer en constante movimiento a lo largo de su vida. En un inicio realizó traslados internos; es decir, entre diferentes ciudades del estado de California y de la región del oeste en el contexto de su trabajo de colaboración con los exiliados mexicanos del Partido Liberal Mexicano. Al principio, su esposo la acompañaba en sus viajes, debido a los intereses profesionales y políticos de éste. Sin embargo, conforme la escritora se adaptó y arropó la causa de la revolución en México, podemos reconocer un ejercicio de autonomía y de movimiento que la llevó, por ejemplo, a viajar a Arizona y establecerse ahí al lado de su amiga y camarada de lucha Elizabeth Trowbridge. El viaje no sólo implicó el trayecto, sino el lugar al que arribaron y su exploración. De nueva cuenta, el hábito de la exploración se ve reflejado en la escritura literaria y en las memorias de Ethel cuando describe sitios, paisajes, cañones e iglesias en medio del desierto (AEDT-INAH, Caja 1: Doc. 137; AEDT-INAH, Caja 6: Doc. 1230; Wood, 1909).

Posteriormente hizo de los viajes un medio de inspiración para su producción literaria. Si el traslado de la casa paterna a la universidad en Berkeley fue elemento sustancial para escribir y publicar su primera novela -One Way Ticket (1934)-, sus dos estancias en Europa en los primeros años de la década de 1930 también influyeron en su obra. Para ella, sus viajes eran "una inversión" para sus escritos, unos publicados (EDT-Banc, Carton 1; Duffy Turner, 1942) y otros que se quedaron como trabajo inédito (Duffy Turner, 1936). Estos nuevos espacios, experiencias de conocimiento y de exploración también están ligados con su compromiso político de izquierda. Ethel es mayormente conocida por su trabajo de colaboración al lado del Partido Liberal Mexicano; sin embargo, su involucramiento en el Frente Popular en las décadas de 1930 y 1940 la llevó a incorporarse al antifascismo. Esta actividad política que está anclada en la solidaridad internacional le permitió pensar en otros espacios, viajar mentalmente a lugares como España, para imaginar propuestas literarias (EDT-Banc, Box 1). ${ }^{8}$

\footnotetext{
8 Mary B. Underwood a Jacques Chambrun, Nueva York, 18 de marzo de 1947.
} 


\section{Género, activismo político y espacios contraculturales desde la bohemia}

Las primeras décadas del siglo $X X$ se caracterizaron, al menos en California, por una importante movilización política desde los socialismos, el movimiento obrero y de mujeres. Además, desde finales del siglo anterior se desarrolló una movilización reformista sin precedente en el marco de la Revolución Industrial y el desarrollo capitalista, que reforzó las desigualdades sociales, vistas y denunciadas por hombres y mujeres preocupados por la salud, la alimentación, la explotación laboral, la corrupción y otros temas de orden social (Robertson, 2004: 1). Conocida como la Progressive Era por la historiografía estadounidense, esta época se caracterizó por la habilidad social para la organización y la manifestación pública; las mujeres fueron protagonistas.

A Ethel Duffy Turner la podemos identificar enlazada con varios movimientos políticos e ideológicos del momento. Por un lado, la encontramos como miembro no formal del Partido Socialista de Estados Unidos, debido al vínculo sentimental con John Kenneth Turner, quien ya tenía años de militante. En realidad, Ethel encontró en el trabajo de apoyo a la causa del Partido Liberal Mexicano y la revolución en México una forma de reconocerse desde posturas ligadas a un socialismo que empataba más con un amplio humanismo en donde "la cultura, la belleza, la alegría y el romance..." (Shaw Peterson, 1993: 33) formaban parte del sentido de justicia que mujeres como ella reconocían a ras de suelo, alejado de la ciencia política (De Vries, 1979: 369). Por el otro, la escritora se comprometió siempre con las causas de pueblos o naciones en lucha desde la solidaridad internacional; su primera experiencia en ese sentido fue con el PLM, que le sirvió para solidarizarse con la revolución nacionalista irlandesa, así como con el bando republicano español durante la Guerra Civil.

Junto a ella había hombres y mujeres que pertenecían al amplio abanico de movimientos sociales que encontraban puntos de encuentro y de lucha. Particularmente, en el caso femenino de este activismo podemos ver a mujeres comprometidas con el socialismo, el anarquismo y el movimiento obrero y al mismo tiempo con la lucha y emancipación de las mujeres, ya fuera desde el sufragismo o desde visiones mucho más abiertas de liberación femenina. Mother Jones, Frances Noel, Emma Goldman y Elizabeth Trowbridge son algunas mujeres que cruzaron caminos e ideas con Ethel. Todas estas experiencias le proporcionaron un extenso capital cultural.

Una vida no tiene una trayectoria lineal, en ella confluyen transformaciones en la toma de decisiones, caminos trazados y encuentros que la complejizan con el paso del tiempo. Otro aspecto que se debería destacar para poder entender los perfiles de mujeres de izquierda, comprometidas con el cambio social, es el de su vinculación con movimientos y espacios contraculturales; particularmente las bohemias. La bohemia es producto de la modernidad, es un fenómeno social y cultural que tuvo sus orígenes a mediados del siglo XIX en Francia, expandiéndose rápidamente a otros lugares como Estados Unidos, donde se concibieron espacios alternos a la cultura hegemónica moderna, urbana, burguesa, ligada al consumismo y las dinámicas propias de la modernización y la industrialización de la época (Burgess, 1902: 128-132). En esta historia destacan particularmente bohemias como la de Greenwich Village en Nueva York. No obstante, Levin (2009) apunta que a finales del siglo XIX existían en el país asociaciones que habían creado "versiones regionales" (Levin, 2009: 676). Durante esta época la bohemia en la ciudad de San Francisco fue destacada, de la mano de figuras fundadoras como Mark Twain y Ambrose Bierce (Hahn, 1967: 71). El interés por estos espacios despuntó en la década de 1890, gracias a la publicación de literatura, revistas y periódicos que abundaban en los significados de la bohemia, sus figuras, objetivos y alcances (Walsh, 2001: 54; MacLeod, 2018: 14).

De origen las bohemias fueron masculinas, conformadas por escritores, artistas, 
profesores universitarios y profesionistas en general. Para las mujeres era complicado acceder: su trabajo era menospreciado o demeritado en función de su aspecto físico. De la afamada escritora Mary Austin los bohemios de San Francisco decían que ella "estaba escribiendo cosas hermosas, pero no era bonita..." (Orth, 1969: 200). Michael Orth apunta que este rechazo llevó a Austin a pensar en otro lugar de la costa californiana para poder inspirarse. De esta acción derivó que George Sterling la acompañara a Carmel By the Sea, un antiguo pueblo de misión, el cual se convirtió a principios del siglo XX en una nueva bohemia para la comunidad artística y literaria (Orth, 1969: 201).

La presencia de una mujer como Mary Austin -fuera del arquetipo hegemónico de feminidad, que vestía atuendos indígenas, con gran éxito literario para la época, autosuficiente y con gran independencia de movimiento- marcó a Carmel. La bohemia dejó de ser eminentemente masculina en el contexto de la incorporación de las mujeres a diferentes espacios anteriormente vetados por su condición de género, y gracias a su pertenencia a clubes, organizaciones artísticas y literarias, como lo hemos apuntado líneas arriba.

La bohemia ofrecía posibilidades alternas: al trabajo intelectual y artístico, a renovadas formas de socialización y generación de vínculos, así como a construcciones autorreferenciales fuera del marco normativo moral de la sociedad a la cual pertenecían sus integrantes. No es extraño que los bohemios carmelitas recibieran críticas e incomodaran a ciertos sectores de la sociedad californiana por su carácter autocomplaciente y su proclividad a la vanidad y a la procrastinación (Newberry, 1910). Para algunos de sus críticos, en la colonia se detenía el tiempo del pensamiento y su evolución; creían que el exceso de calma y el aislamiento de la realidad provocaba estancamiento productivo (Gilliam y Gilliam, 1992: 99).

El paso por la bohemia de Ethel Duffy Turner dice lo contrario. Con una estancia en Carmel de al menos cinco años, es posible identificar con claridad un importante desarrollo y madurez intelectual en donde las artes como la pintura, el teatro y la producción poética van a ser prioritarias y esenciales en esta etapa de su vida, como se puede ver en los registros documentales de su archivo personal (EDT-Banc-Scrapbook, BANC PIC 1974.049-fALB; EDT-Banc, Carton 1). ${ }^{9}$ Por ejemplo, junto a otras mujeres se abocó a la pintura, particularmente en el aprendizaje del impresionismo de la mano de connotados artistas como WiIliam Merrit Chase; se inscribió a cursos y talleres que la llevaron a realizar estancias en Pasadena, California. Sus obras destacaron por el gusto por los paisajes al aire libre con figuras. Disfrutaba dando paseos a lo largo de la playa y el bosque de Carmel en busca de escenas para su trabajo artístico (Duffy Turner, 1967: 37). La posibilidad del ejercicio de la contemplación, de tomarse un espacio natural como cuarto propio para crear, deben ser elementos para considerar en las transformaciones que están teniendo lugar en la vida de muchas mujeres durante la época. La bohemia lo posibilita. Asimismo, participar en la producción de obras de teatro al aire libre, en medio del bosque de Carmel, la llevó a descubrir habilidades multifacéticas mediante la actuación y a expandir los límites del cuerpo al momento de entrar a escena. Por otro lado, fue en esta actividad donde las mujeres pasaron por conflictos de género al momento de poder incorporarse no sólo como actrices, sino como guionistas y directoras de las obras que se presentaban anualmente en el lugar.

El Forest Theatre y sus organizadores, la mayoría hombres, decidían la obra de teatro que se montaba cada año. En 1912, Carmel llegó a las noticias de los periódicos de San Francisco por la incógnita en torno a la obra de teatro "The Toad". El manuscrito había sido dejado en una canasta rodeada con un listón rosa en la casa del secretario de la Forest Theatre Society. No había remitente, ni autor de la obra. Al leerla, los miembros de la sociedad consideraron que era un manuscrito adecuado para ser montado por su

9 "Ethel Duffy Turner Scrapbook"; "Notes Early Literary Carmel”. 
carácter viril; creían que el guion había sido escrito por un hombre. Al poco tiempo, la escritora y miembro de la bohemia carmelita Bertha Newberry, reveló ser la autora. George Sterling y otros inmediatamente la acusaron de plagiaria, lo que desató toda una disputa al respecto (Anónimo, 1912a). El apoyo recibido de un grupo importante de la bohemia, en su mayoría mujeres, logró que la obra se eligiera para ser llevada a escena con éxito (Anónimo, 1912b, 1912c, 1912c). Austin también tuvo ciertas desavenencias con Sterling respecto al montaje de "The Arrow Maker" (Dramov, 2012: 183). Cabe señalar que en ambas obras participó Ethel Duffy Turner.

Las mujeres ya no estaban dispuestas a ceder los espacios ganados en la bohemia. La organización y el apoyo mutuo se volvió una constante en la dinámica de la comunidad artística. Asimismo, lograron organizarse para proteger lo que ellas consideraban como espacios seguros, libres de violencia o peligros por su condición de género. En 1914 exigieron una investigación en torno a la desaparición de la artista Helena Wood Smith. Las investigaciones, según la prensa, señalaron que había sido víctima de un homicidio por parte de su pareja sentimental, el fotógrafo George Kodani. Tras conocer el fatídico desenlace de su compañera, solicitaron seguridad para las aproximadamente 100 mujeres, visitantes y residentes, de Carmel. Sobre todo, para aquellas que vivían solas (Anónimo, 1914).

A pesar de la obstinación de quienes ostentaban el papel de líderes o fundadores de la comunidad, conforme pasaba el tiempo, las mujeres de forma inevitable estaban en todos los espacios de la vida social y artística de la bohemia. Ya no sólo eran las actrices de las obras de teatro, también fungían como escenógrafas, escribían y dirigían obras.

Asimismo, montaban exposiciones y practicaban actos de solidaridad entre ellas para salvaguardar su seguridad. Por otro lado, habría que señalar que el perfil de estas mujeres no encajaba del todo con el ideal femenino; la prensa las describía como mujeres "menos conservadoras", de "apariencia excéntrica", quienes danzaban con pies descalzos, moviendo sus cabezas con cortes de cabello a la garconne, en un momento cuando apenas se comenzaba a posicionar este estilo, tan atractivo para las jóvenes una década después (Anónimo, 1951a; Anónimo, 1951b; Robbins, 1967).

Eran mujeres que habían tenido experiencia en el activismo político como Ethel, pero también aquellas que habían pertenecido a comunidades utópicas de corte socialista (EDT-Banc, Carton 1). ${ }^{10}$ Como ya se señaló, algunas vivían solas, habían construido sus cabañas, eran autosuficientes, pues se sostenían de su trabajo literario y artístico. Austin creía que quienes tenían talento debían liberarse, para la escritora el amor no era suficiente para completar la vida entera de una mujer (Robbins, 1967). Definitivamente, todo este cúmulo de prácticas, visiones de la feminidad desde el espacio contracultural de la bohemia definieron, en parte, la vida de Ethel. Sin duda, su poema "An Artless Maid", el cual escribió y fue publicado durante su etapa carmelita, es producto de esta impronta de vínculos femeninos bohemios.

\section{Del amor y otras emociones y vínculos}

En Carmel, el vínculo sentimental entre Ethel Duffy y John Kenneth Turner se modificó y se fracturó hasta llegar al divorcio en 1917. Aunque no tenemos claridad sobre todas las causas que llevaron a la desintegración del matrimonio, podemos señalar algunas. Cuando se conocieron John Kenneth Turner ya había alcanzado experiencia en el activismo socialista y en el periodismo de denuncia que desarrolló desde edad temprana, mientras que Ethel era una joven ávida de conocimiento, con cierta atracción por el reformismo social, pero con poca o nula experiencia, lo que de alguna manera contribuyó a que ella se acomodara a la agenda e intereses de él, para después empaparse de las prácticas de la lucha, apropiarlas y

10 Ethel Duffy Turner, "Notes on Literary Carmel", [manuscrito]. 
reconfigurarlas a partir de sus intereses políticos y literarios. En ese sentido, tenemos a Turner como una figura preponderante a nivel nacional por su actividad periodística que lo llevó a estar largas temporadas ausente. De alguna manera, la dinámica familiar estaba compuesta mayoritariamente por la relación entre Ethel y su hija Juanita (1909-1974) (EDT-Banc-Scrapbook). ${ }^{11}$

En realidad, la relación estuvo circunscrita al contexto del activismo y a la bohemia, lo que generó un vínculo particular entre ellos. Incluso, cuando se conocieron el primer contacto fue producto de una pequeña nota que el joven le envió a la estudiante universitaria en la cual la invitaba a evitar la formalidad del cortejo victoriano en donde era necesario de un intermediario para introducirlos mutuamente (AEDT-INAH, Caja 4, Exp. 716). ${ }^{12}$ No obstante, Turner no podía sustraerse de una cultura masculina e ideas tradicionales del matrimonio, donde la mujer era considerada como el apéndice del hombre. En una carta escrita a su viejo camarada mexicano Antonio I. Villarreal, John escribió que se había casado de nuevo. Para el escritor socialista su nueva esposa "se preocupa por mí más que Ethel. Es encantadora y creo que te gustará. Ella irá a donde yo vaya..." (AIV-IIS-UNAM, Caja 6). ${ }^{13}$ En la misiva, el escritor se quejó del arrebato de Ethel por abandonarlo y partir hacia San Francisco. Ese arrebato emocional muy probablemente estuvo ligado al descubrimiento de una infidelidad. No es fortuito que unos meses después de su separación, en el mismo año de 1917, el periodista se haya casado, sigilosamente según la prensa, con la escritora Adriana Spadoni (Anónimo, 1917).

Griswold (1980), en su estudio sobre el divorcio en California durante la segunda mitad del siglo XIX, identificó una constante en las deserciones de mujeres de sus matrimonios - abandono de la relación marital-, acciones por las cuales eran denunciadas (Griswold, 1980: 268). Por su parte, DiFonzo encuentra que, para la década de 1920, ha-

11 "Dibujos Ethel y Juanita, Carmel 1915".

12 John Kenneth Turner a Ethel Duffy Turner, s/f.

13 John Kenneth Turner a Antonio I. Villarreal, 25 de diciembre de 1918. bía tenido lugar una "modulación del rol de la mujer". El cambio de siglo en el marco de la Progressive Era, el acceso a la educación superior femenina, el aumento del trabajo femenino producto del desarrollo industrial y la sociedad de consumo antes y durante el periodo de guerra, generó una sensación entre las mujeres de liberación del "feudo financiero que había constreñido los matrimonios de sus madres" (DiFonzo, 1997: 17). Existía un ambiente, en la cultura popular del momento, que ofrecía a las mujeres la posibilidad de salir de un matrimonio desagradable porque, en apariencia, contaban con más posibilidades para sobrevivir económicamente (DiFonzo, 1997: 17). Cuando Ethel se separó de su esposo había un debilitamiento considerable del tabú en torno al divorcio en la sociedad (DiFonzo, 1997: 17).

El divorcio en Estados Unidos tuvo una continua alza en los porcentajes de solicitudes por parte de mujeres, desde la segunda mitad del siglo XIX hasta las dos primeras décadas del siguiente siglo (Schweizer, 2020: 1). El contexto para las mujeres divorciadas o separadas podía ser hostil, sobre todo en el aspecto económico. No obstante, recurrían a redes de apoyo de familiares o amigos (Griswold, 1980: 273), lo que les permitía sortear el complicado proceso de adaptación y supervivencia. Ethel recurrió a su familia, que la socorrió en el proceso.

$\mathrm{Si}$ "las emociones forman la personalidad y la modifican" (Fucé, 2017: 121), los efectos de la separación llevaron a Ethel a tomar decisiones que no tenía contempladas, las cuales incidieron en la forma en la cual ella reprimía o desvalorizaba sus propias emociones con argumentos que la llevaban a comparar la depresión, la tristeza o los problemas mentales, como ella los describía, con el sufrimiento y los padecimientos de personas víctimas de la desigualdad y la explotación en el mundo (EDT-Banc, Box 1). ${ }^{14}$ Producto de estos cambios, la relación de la escritora con la maternidad también se modificó. La redefinió a partir de dos variables: la necesidad imperiosa de trabajar y

14 Ethel Duffy Turner a John Kenneth Turner; San Francisco, California, 2 de diciembre de 1919 
su deseo de hacer una carrera literaria. San Francisco era el lugar idóneo para lograrlo a costa de dejar a cargo de sus padres la crianza de Juanita (AIV-IIS-UNAM, Caja 6).15

Si analizamos desde la distancia la etapa posterior al divorcio en la vida de Ethel Duffy Turner, es sencillo percatarnos de que, a pesar de las primeras dificultades, logró consolidar una carrera literaria en San Francisco gracias a las redes de la bohemia, así como a su imparable búsqueda de espacios para publicar su poesía y propuestas literarias. Fue en este periodo cuando publicó su primera novela. Asimismo, durante las décadas que van de 1920 a 1940 tuvo la oportunidad de reafirmar su lugar en el abanico de las izquierdas en su vinculación con el Frente Popular y la solidaridad internacionalista con movimientos revolucionarios y antifascistas en Irlanda y España, respectivamente. Sin duda, su nueva condición civil le permitió trazar senderos propios, crecer y madurar intelectualmente.

\section{Mujeres que escriben sobre/para mujeres. Escritura desde las experiencias de vida}

Otra moralidad surgió a partir de la década de 1920, tras la finalización de la Primera Guerra Mundial (Bogart, 1969: 9). La mujer moderna era una realidad, gracias a un proceso de emancipación femenina que se produjo en el cambio de siglo y en el contexto de un activismo reformista y de izquierda inusitado, como ya lo hemos planteado. Incluso durante esta época la imagen de la femme fatale propuesta desde el cine y la literatura era acompañada de un nuevo arquetipo que inundó las revistas y los objetos de consumo: las flappers, mujeres jóvenes que desafiaron desde lo corporal y lo simbólico el espacio público con su melena a la garçonne y una primera revolución sexual (Hallet, 2011: 182). Lo que mujeres vanguardistas de la bohemia habían implementado unos años atrás, se había extendido presurosamente en los centros de trabajo, las universidades y en las calles. No obstan-

15 John Kenneth Turner a Antonio I. Villarreal, 25 de diciembre de 1918. te, estas imágenes y construcciones de una nueva feminidad no eran homogéneas y estaban cargadas de contradicciones y diferencias cuando eran cruzadas por la clase y el origen étnico (Willey Todd, 1993: 3; Jensen y Ricci, 1987: 76).

Después de que el movimiento sufragista consiguiera el voto en 1920 -en California la decimonovena enmienda se aprobó a finales de 1919-, se asume historiográficamente que hay un retraimiento del feminismo (de aquí la metáfora de las olas). No obstante, habría que matizar esta aseveración y plantear que el movimiento de mujeres no sólo obedecía a la búsqueda del voto, sino también a otras preocupaciones ligadas a las relaciones familiares, el control de la natalidad, la igualdad laboral, el acceso a la educación. Expósito plantea la emergencia, en este periodo, de un "feminismo más individualista que el anterior", debido a los cambios "en el trabajo, la sexualidad, el matrimonio y el consumo, pero también el auge de las ciencias sociales y de las profesiones [...]" (Expósito García, 2016: 111).

Hay un cambio en las percepciones de las mujeres sobre sí mismas, que alienta la autosuficiencia(Expósito García, 2016: 75). Mujeres que no podemos ver vinculadas explícitamente al sufragismo, como Ethel, pero que vivieron, experimentaron e hicieron suyos nuevos paradigmas del ser mujer y que se volvieron evidentes en aquellas que utilizaron la pluma para hablar desde su propia sensibilidad al contemplar y apropiarse de espacios; y crear personajes ficcionales femeninos que recuperaron a la nueva mujer, desde sus propias experiencias de vida.

San Francisco le proporcionó a Duffy Turner una fuente de inspiración casi inagotable. Su incorporación al mercado laboral como oficinista le dio la oportunidad de poner en práctica el acto de la contemplación a causa de la constante movilidad. Era una habitación propia sin puertas y ventanas que le permitió registrar lo observado y explorado para traducirlo en versos poéticos para el San Francisco Call. Por otro lado, el poeta George Sterling la introdujo a las redes de intelectuales que fueron sustanciales 
para posicionarse en la escena literaria de la bahía (EDT-Banc, Box 1). ${ }^{16}$ Sin tiempo que perder, Ethel se incorporó a la bohemia de San Francisco mediante su inscripción a clubes artísticos y literarios como el Seven Arts Club, el Poetry Club y el Stage and Studio Club (EDT-Banc, Box 1)..$^{17}$

A comienzos de la década de 1920 en California se contabilizaban cientos de clubes de mujeres con diferentes fines e intereses. Era parte de una historia consolidada de asociacionismo femenino en el estado que databa de mediados del siglo XIX. Había clubes que promovían actividades ligadas a los roles tradicionales con sutiles contrastes (Lyons y Wilson, 1922: VII), frente a otras organizaciones que representaban la transformación de la mujer que había abandonado su extensa falda de campana y la tutela económica paterna, por una nueva mujer segura, vestida para su trabajo en la oficina, con dinero y el reciente derecho al voto en los bolsillos (Lyons y Wilson, 1922: 167).

Entre las décadas de 1920 y 1930 podemos destacar un proceso de madurez intelectual por parte de Ethel Duffy Turner. Después de publicar la columna de poemas, se asoció con el escritor socialista William Aberle para editar la revista de poesía The Wanderer. Aberle proporcionaba el recurso financiero y Ethel toda la parte creativa y el trabajo editorial; la revista fue producto directo de su trabajo y experiencia (Duffy Turner, 1967: 41). En su rol de editora logró incorporar el talento de mujeres, ofreciéndoles un espacio para publicar su obra (Turner, 1924a, 1924b). Asimismo, escribió para la revista varios ensayos críticos sobre el quehacer literario, reflexiones sobre sus deseos intelectuales y el lugar que ella se otorgaba como autora.

En sus textos defendía la originalidad de su escritura sin darle peso al exterior, es decir, a la audiencia. Para ella el verdadero artista era individualista, navegaba solo y se atrevía a marcar diferencias, aunque esto implicara el rechazo del público y el sacrifi-

16 Ethel Duffy Turner a John Kenneth Turner; San Francisco, California, 2 de diciembre de 1919.

17 Ethel Duffy Turner, "Stage and Studio Club", [manuscrito]. cio del éxito en pos de la autonomía creativa (Duffy Turner, 1923).

Pero el éxito llegó a Ethel Duffy Turner gracias a la publicación de su novela OneWay Ticket en 1934, la cual, en general, fue recibida de forma positiva por la crítica. A pesar de ser su primera obra, se consideró como un buen comienzo literario (EDTBanc, Carton 1; Hansen, 1934). ${ }^{18}$ Fue calificada como una novela realista desde una mirada particular y original (Ballantine, 1934) y a ella como una autora prometedora (EDT-Banc, Carton 1)..$^{19}$ La obra es considerada de corte autobiográfico, ya que recrea la época de su adolescencia en la casa familiar bajo la dinámica de sociabilidad que ofrecía la colonia de trabajadores de la prisión de San Quintín. Para Ethel, salir de su pueblo e ir a la universidad le permitió eliminar prejuicios en torno a los presos, ya que logró percatarse de las causas sociales que llevaban a los seres humanos a cometer crímenes (EDT-Banc, Box 1). ${ }^{20}$ Por otro lado, la novedad de la obra fue aderezada por el anuncio de que sería llevada al cine. La película fue dirigida por Herbert Biberman y estrenada en 1935. (Duffy Turner, 1967: 43; Anónimo, 1934a; Anónimo, 1934b). Eran los primeros años de la depresión económica producto del crack financiero de 1929. Gracias a la venta de los derechos de la novela vivió esta etapa crítica con bastante holgura, al grado de que realizó un viaje a Europa (Duffy Turner, 1967: 46).

La escritura de Ethel Duffy Turner se alimentó de la experiencia, así como de temas con problemática social o que le provocaron reflexiones de tipo existencial en torno a la condición humana. Su vínculo con el activismo político y revolucionario de izquierda están reflejados en posteriores intentos literarios que no llegaron a buen puerto por el rechazo de la industria editorial por ser temas muertos para la década de 1940 18 James T. Farrell, "A Novel not of Prison Life but of Life within a Prison's Shadow", [recorte de periódico], 1937, "One Way Ticket Reviews".

19 John D. Barry, "Prison life intimately depicted", [recorte de periódico], 21 de marzo de 1934, "Notes One Way Ticket".

20 "Writer gives up CWA School Job as Novel Scores Hit", [recorte de periódico], circa 1934-136. 
(EDT-Banc, Box 1). ${ }^{21}$ Dos novelas fueron y vinieron de editoriales sin éxito: Four Green Fields y Goodbye Now. Ambas ambientadas en tiempos convulsos; la primera es protagonizada por una joven de orígenes irlandeses que se involucró en la revolución de independencia de Irlanda (EDT-Banc, Box 1). ${ }^{22}$ La segunda, una historia ambientada en la Guerra Civil española (EDT-Banc, Box 1). ${ }^{23}$ Para esa época Ethel ya había colaborado en organizaciones irlandesas en San Francisco, desde las cuales dio su apoyo a ambos conflictos desde la solidaridad internacionalista, apoyando a líderes activistas como Maud Gonne en Irlanda y realizando trabajo de recaudación de apoyo para las brigadas internacionales en la guerra en España por medio del Irish Committee in Defense of Spain. ${ }^{24}$

En medio de la organización del Frente Popular -movimiento político, social y cultural que trascendió su origen ligado al Partido Comunista en Estados Unidos(Denning, 1998: 26; Mickenberg, 2006: 284), Ethel se involucró por completo en la lucha antifascista antes y durante el marco de la Segunda Guerra Mundial. Su incorporación a la League of American Writers y sus colaboraciones para la revista de la izquierda cultural New Masses (Bernardete y Humphries, 1937) fueron algunas de las redes que consolidó en este periodo y que están reflejadas en su producción intelectual inédita (Marie L.-Banc, Box 4). ${ }^{25}$ La escritora perteneció a una generación forjada en la edad de oro del socialismo estadounidense que convivió con otra ligada al Partido Comunista (fundado en 1919), las cuales encon21 Mary B. Underwood a Jacques Chambrun; Nueva York, 18 de marzo de 1947.

22 He reconstruido esta descripción general de la novela a partir de la correspondencia sostenida entre Ethel y el editor Harrison Smith; incluye las sugerencias hechas por éste para ajustar y fortalecer la historia. Harrison Smith a Ethel Turner, Nueva York, 30 de enero de 1935.

23 Mary B. Underwood a Jacques Chambrun; Nueva York, 18 de marzo de 1947.

24 Maud Gonne McBridge a Ethel Turner, s/l, s/f, circa 1937 (EDT-Banc, Box 1); Ethel Duffy Turner a Marie Welch, San Francisco, 18 de abril de 1937; Marie L.Banc, Box 1.

25 Ethel Turner a Marie Welch; San Francisco, 18 de abril de 1937. traron puntos de diálogo en su lucha contra el fascismo, el racismo, el imperialismo y el intervencionismo en la década de 1930.

Las mujeres ligadas a la lucha desde el movimiento de izquierda, así como del vanguardismo de la bohemia, tuvieron la posibilidad de explorar amplios campos de acción desde el activismo, las artes y la literatura. No obstante, y a pesar de cierta apertura recibida al interior de las organizaciones, clubes y grupos a los cuales pertenecían, seguían padeciendo las dificultades para publicar su trabajo intelectual. Si, como Ethel, querían sostener una narrativa poco apegada a ciertos cánones literarios, se encontraban ante el riesgo de que se les cerraran puertas, el ostracismo, o que cosecharan un público exclusivamente femenino (Expósito García, 2016: 264).

Personajes empoderados, rebeldes, revolucionarios, transgresores, están presentes en las obras de escritoras como Ethel Duffy Turner. Literatura que cuestionó cánones y formas de exponer a las mujeres como protagonistas, desde una concepción feminista amplia, a partir de una narrativa que iba de los ficcional, pasando por el realismo y lo autobiográfico. Factores que son la causa para explicar los rechazos, las entradas y salidas de una editorial a otra. Otras escritoras estadounidenses que padecieron las dificultades para publicar su propuesta literaria, como Djuna Barnes, o para encontrar espacios teatrales para representar sus obras, como Sophie Treadwell, son ejemplos que nos permiten apreciar las resistencias y tensiones en medio de las transformaciones propias de la condición de la mujer moderna (Expósito García, 2016: 282; Narbona Carrión, 2007).

A partir de la década de 1940 en el ambiente de posguerra y de ansiedad anticomunista, la persecución y el cierre de espacios para una amplia gama de expresiones que se habían consolidado desde el Frente Popular y las políticas del New Deal, limitó el trabajo de artistas e intelectuales en general. La posguerra también traería consigo la conformación de una cultura y sociedad conservadora que promovía, mediante la 
literatura y los medios de comunicación, el retorno de las mujeres al ámbito doméstico, al tiempo que se difundía y revalorizaba otro arquetipo: el de la sensual y extremadamente femenina pin-up.

Las revistas y la literatura para mujeres se modificaron entre 1940 y 1950. La protagonista autónoma y revolucionaria de la década de 1930 fue cancelada en el mainstream de la cultura popular. Por consecuencia, jubilaciones, retiros a temprana edad y desaparición de editoriales a cargo de mujeres tuvieron lugar durante el periodo: "Los nuevos profesionales de las revistas eran hombres y unas cuantas mujeres que se sentían cómodas escribiendo de acuerdo con la fórmula del ama de casa" (Friedan, 2009: 92). La primavera de las mujeres de las tres primeras décadas del siglo $X X$ se vio opacada por las permanencias patriarcales en torno al lugar de la mujer en la sociedad; estamos ante transformaciones que tocaron cosmovisiones, normas sociales y prácticas culturales establecidas que resistieron, por su pertenencia a la larga duración.

\section{Consideraciones finales}

Las mujeres durante las primeras tres décadas del siglo XX en Estados Unidos, transitaron por varios procesos de emancipación de la mano de su vinculación con otros movimientos sociales y políticos. Particularmente, mujeres situadas en el espectro de las izquierdas, como Ethel Duffy Turner, van a acentuar y expandir los roles sociales desde el activismo, por un lado, y las experiencias ligadas a lo contracultural como las bohemias, por el otro. Si entendemos el feminismo como un movimiento de mujeres que no sólo estuvo enmarcado en la lucha sufragista, sino en intereses ligados a la igualdad de la mujer en los diferentes ámbitos sociales, incluidos los del espacio privado, podemos reconocer que estamos ante un proceso de configuración de otras formas de feminidad, desde nuevas prácticas de autonomía, libertad y emancipación.

La apertura de espacios educativos, laborales y posibilidades de producción in- telectual, contribuyó a un estiramiento de la formación de una conciencia femenina entre varias generaciones de mujeres en el cambio de siglo. Aunque el derecho al voto fue conseguido en Estados Unidos en 1920 y cerró una etapa de la lucha de las mujeres, no significó la desintegración del feminismo y sus ideas. Hubo mujeres que siguieron trabajando en favor de la igualad laboral, el control natal, así como desde movimientos políticos y culturales como el comunismo o el socialismo. Por otro lado, el feminismo puede también adjudicarse a los cambios de paradigmas de las mujeres de la época, desde donde pusieron en prácticas formas alternas de sociabilidad y expresión artística e intelectual.

Ethel Duffy Turner encarna a las mujeres modernas de las primeras tres décadas del siglo XX. Las bohemias, el activismo socialista y la incorporación a diferentes ámbitos de lucha por la justicia social son producto de la modernidad como proceso de transformación política, económica y sociocultural. En el transcurrir de su vida, Ethel se topó con ideas del feminismo de la época que de manera directa e indirecta incidieron en su desenvolvimiento como activista y escritora. Podemos situarla en la vanguardia, como a otras, de un momento histórico único y extraño que va a apuntalar un proceso ininterrumpido de novedad y experimentación de estilos de vida cosmopolitas, móviles y alternativos para las mujeres (Expósito García, 2016: 74).

La exploración de diferentes facetas de su trayectoria nos permite identificar los ámbitos de incidencia de las transformaciones que trajo consigo el movimiento de emancipación femenina. No sería osado pensar estos ejes para otras realidades y trayectorias paralelas que vivieron este ciclo de cambios; no sólo de mujeres estadounidenses, sino de otros espacios nacionales destacando sus diferencias y matices contextuales.

En el caso de Ethel Duffy Turner, el acceso a la educación superior por parte de su generación fue un elemento sustancial para el proceso de conformación de una cultu- 
ra escrita que se ampliaría al momento de la incorporación al espacio laboral y, a su vez, le permitiría incursionar en la creación poética y literaria en periódicos y revistas a lo largo de tres décadas. Por otra parte, al transitar en el activismo, desde la solidaridad internacional, adquirió experiencias y conocimiento que le proporcionaron ideas para proponer novelas en donde el común denominador eran mujeres modernas inmersas en agitaciones políticas y revolucionarias. La propuesta intelectual de mujeres como Ethel linda en la frontera de la autobiografía, la recuperación del realismo social y la ficción para presentar protagonistas autoafirmativas.

Estos referentes pudieron ser también recuperados a partir de su profunda asociación con la bohemia. Como espacios que navegan a contracorriente de los modelos culturales hegemónicos en tensión y transición, la bohemia fue un bálsamo para las ansiedades que producía la modernidad entre hombres y mujeres que intentaron consolidar identidades de género en espacios alternos de sociabilidad. Las mujeres, en particular, probarían la generosidad de las posibilidades creativas alrededor del arte y la literatura. Asimismo, lugares como Carmel By the Sea facilitaron que escritoras y artistas en general exploraran las expresiones corporales a través del teatro y la incorporación de indumentaria, cortes de cabello y rituales que no encajaban en los ideales victorianos que se resistían al cambio.

Las nuevas expresiones del ser mujer también se reflejaron en las relaciones interpersonales. Cuando Ethel Duffy Turner decidió separarse del periodista John Kenneth Turner, transitó por un proceso complejo que la llevó a tomar decisiones por necesidad económica que reconfiguraron su relación con la maternidad y sus prioridades como mujer en busca de una habitación propia y todo lo que esto implicaba (autosuficiencia económica, independencia creativa, redes y espacios para exponer su obra). Eran actos de rebeldía personal que trascendían lo privado.
No obstante, la paranoia anticomunista de la posguerra, a partir de la década de 1940, alentaron y avivaron las resistencias conservadoras en Estados Unidos. Lo que Betty Friedan identificó como una mística de la feminidad, eran las expresiones y malestares de una generación posterior a la de Ethel, criada en las contradicciones y los efectos de un importante retraimiento a los roles tradicionales. Mientras los hogares eran objeto de la modernización, por medio de la tecnología y la expansión de la clase media en medio de la bonanza económica del periodo, se extendía un "malestar" que no tenía nombre.

Las generaciones anteriores, revolucionarias, progresistas, eran mujeres de una vanguardia que había continuado y ampliado la lucha de las antepasadas decimonónicas por la igualdad de condiciones femeninas. Dentro de ese nuevo contexto conservador que se tornó hegemónico, por su incorporación a la cultura popular, se toparon con la reconfiguración editorial y del mercado de lectores. No es extraño que después de los múltiples rechazos editoriales que Ethel Duffy Turner recibió, volteara de nuevo su mirada a México, abandonara la literatura por la historia de la época en la que colaboró con el Partido Liberal Mexicano; momento bisagra en su vida que la marcó profusamente como una mujer moderna.

\section{Fuentes consultadas}

\section{Archivos}

AEDT-INAH Archivo Ethel Duffy Turner, Biblioteca Eusebio Dávalos, Instituto Nacional de Antropología e Historia.

AIV-IIS-UNAM Archivo General Antonio I. Villarreal, Instituto de Investigaciones Sociales, Universidad Nacional Autónoma de México.

EDT-Banc Ethel Duffy Turner Papers, Bancroft Library, Departament of Special Collections, University of California, Berkeley. 
EDT-Banc-Scrapbook Ethel Duffy Turner y Fredericka Martin en las 14 Casas, Bancroft Library, Universidad de California/Casa de El Hijo del Ahuizote.

Marie L.-Banc Marie Laveaga Welch Papers, Bancroft Library.

\section{Referencias}

Anónimo (1951a), “Tsch...Tsch... Bohemian Early Carmel; Women Danced in Bared Feet...", The Carmel Pine Cone-Cymbal, 30 de marzo, Carmel By the Sea, s/e.

Anónimo (1951b), "Carmel Started as Writers' Group in 1905. Led by George Sterling", The Carmel Pine Cone-Cymbal, 30 de marzo, Carmel By the Sea, s/e.

Anónimo (1934a), "Autor in Prison", The Pittsburgh Press, 27 de marzo, Pittsburgh, E.W. Scripps Company.

Anónimo (1934b), "Autor in Prison", Star-Phoenix, 4 de junio, Saskatoon, Postmedia Network.

Anónimo (1917), "A Wedding at Carmel", Oakland Tribune, 9 de septiembre, Oakland, Bay Area News Group.

Anónimo (1914), "Is Kodama Yamagachi?", Oakland Tribune, 18 de agosto, Oakland, Bay Area News Group.

Anónimo (1912a), "Classic Carmel is Stirred by 'The Toad'", San Francisco Chronicle, 20 de marzo, San Francisco, Hearst Corporation.

Anónimo (1912b), "Carmel Discovers Author of 'Toad", San Francisco Chronicle, 3 de abril de 1912, San Francisco, Hearst corporation.

Anónimo (1912c), "Woman, Author of 'The Toad'", Oakland Tribune, 3 de abril de 1912, Oakland, Bay Area News Group.

Anónimo (1912d), "Greek Theater to Be Scene of Spectacular Drama by Mrs. Newberry", San Francisco Chronicle, 20 de julio, San Francisco, Hearst Corporation.
Anónimo (1905), Berkeley-California a City of Homes, Berkeley, s/e.

Ballantine, Betty (1934), "Ethel Turner Sees Life in San Quentin", San Francisco News, 10 de marzo, San Francisco, s/e.

Bartra, Armando (1980), Regeneración 1900-1918. La corriente más radical de la revolución mexicana de 1910 a través de su periódico de combate, Ciudad de México, Era.

Beatty, Bess (2016), Traveling Beyond her Sphere. American Women on the Grand Tour, 1814-1914, Washington, New Academia Publishing.

Bernardete, M.J. y Humphries, Rolfe (1937), ....and Spain Sings. Fifty Loyalists Ballads adapted by american poets, Nueva York, The Vanguard Press.

Bogart, Max (1969), The Jazz Age, Nueva York, Charles Scribner's Sons.

Burgess, Gelett (1902), "Where is Bohemia?", en Gelett Burgess, The Romance of the Commonplace, San Francisco, Paul Elder and Morgan Shepard.

Cano, Gabriela (2007), "Ciudadanía y sufragio: el discurso igualitario de Lázaro Cárdenas", en Martha Lamas (coord.), Miradas feministas sobre las mexicanas del siglo XX, Ciudad de México, FCE/ Conaculta.

Cano, Gabriela (2006), "Debates en torno al sufragio y la ciudadanía de las mujeres en México", en Guadalupe Gómez-Ferrer, Gabriela Cano, Dora Barrancos y Asunción Lavrin (coords.), Historia de las mujeres en España y América Latina, vol. IV, Madrid, Ediciones Cátedra.

Cano, Gabriela (1996), "Feminismo y nacionalismo", La ventana. Revista de estudios de género, núm. 4, Guadalajara, Universidad de Guadalajara, pp. 38-58.

Cano, Gabriela (1993), "Revolución, feminismo y ciudadanía en México, 1915-1940", en Georges Dubby y Michelle Perrot (eds.), Historia de las mujeres en Occidente, t. 5, Madrid, Taurus. 
Cano, Gabriela (1991), “'En estricta justicia...' Un proyecto feminista en el movimiento constitucionalista", Memoria del Congreso Internacional sobre la Revolución Mexicana, México, INEHRM, Gobierno del Estado de San Luis Potosí, pp. 163-171.

Chassen-López, Francie (1994), "Cheaper than Machines: Women in Agriculture in Porfirian Oaxaca", en Heather Fowler Salamini y Mary Kay Vaughan (eds.), Women of the Mexican Countryside, 1850-1990: Creating Spaces, Shaping Transitions, Tucson, University of Arizona.

De Vries, Lini (1979), Up from the Cellar, Mineápolis, Vanilla Press.

Denning, Michael (1998), The Cultural Front. The Laboring of American Culture in the Twentieth Century, Nueva York, verso.

DiFonzo, J. Herbie (1997), Beneath the fault line. The popular and legal culture of divorce in Twentieth-Century America, Charlottesville, The University Press of Virginia.

Dramov, Alissandra (2012), Carmel by the Sea, the early years (1903-1913), Bloomington, AuthorHouse.

Duffy Turner, Ethel (2003), Ricardo Flores Magón y el Partido Liberal Mexicano, Ciudad de México, Instituto Nacional de Estudios Históricos de las Revoluciones de México, 2003.

Duffy Turner, Ethel (1967), "Writers and Revolutions. An interview", Berkeley, University of California/ Bancroft Library.

Duffy Turner, Ethel (1942), "Eclipse", Story Magazine, mayo-junio, Nueva York, Random House.

Duffy Turner, Ethel (1936), "Down to Her Last Three Cents When $\$ 5500$ Check Arrived!", The San Bernardino County Sun, 16 de febrero, San Bernardino, Southern California News Group.
Duffy Turner, Ethel (1934), One-Way Ticket, Nueva York, Harrison Smith and Roberth Haas.

Duffy Turner, Ethel (1923), "Monsters and Faun", The Wanderer, San Francisco, s/e.

Duffy Turner, Ethel (1913), "An Art-less Maid”, Life, 2 de enero, Nueva York, MitcheIl-Miller.

Duffy Turner, Ethel (1911a), "Uncle Sam", Regeneración, 18 de febrero de 1911, Los Ángeles, Partido Liberal Mexicano.

Duffy Turner, Ethel (1911b), "Not War Game, But War!", Regeneración, 11 de marzo, Los Ángeles, Partido Liberal Mexicano.

Duffy Turner, Ethel (1911c), "Two More Outrages", Regeneración, abril, Los Ángeles, Partido Liberal Mexicano.

Duffy Turner, Ethel (1910a), "Is the Blood of the Fathers of the Revolution in Your Veins", Regeneración, noviembre, Los Ángeles, Partido Liberal Mexicano.

Duffy Turner, Ethel (1910b), "Shall Mexico Be Annexed?", Regeneración, 24 de diciembre, Los Ángeles, Partido Liberal Mexicano.

Expósito García, Mercedes (2016), De la Garçonne a la pin-up. Mujeres y hombres en el siglo XX, Madrid, Ediciones Cátedra.

Fernández-Aceves, María Teresa (2003), "Once we were Corn Grinders: Women and Labor in the Tortilla Industry of Guadalajara, 1920-1940", International Labor and Working-Class History, núm. 63, Cambridge, Cambridge University Press, pp. 81-101.

Fernández-Aceves, María Teresa (2014), Mujeres en el cambio social en el siglo XX mexicano, Ciudad de México, CIESAS/ Siglo XXI.

Friedan, Betty (2009), La mística de la feminidad, Madrid, Universitat de València/ Instituto de la mujer. 
Fowler-Salamini, Heather (2013), Working Women, Entrepreneurs, and the Mexican Revolution: The Coffee Culture of Cordoba, Veracruz, Lincoln, University of Nebraska Press.

Fucé, Pablo (2017), “Emociones y sentimientos en la historia: una agenda abierta de trabajo", Revista sudamericana de Educación, Universidad y Sociedad, 5 (1), Montevideo, Universidad de la Empresa, pp. 119-128, doi: https://doi. org/10.48163/rseus.2017.51119-128

Gilliam, Harold y Gilliam, Ann (1992), Creating Carmel: The Enduring Vision, Salt Lake City, Peregrine Smith Books.

Gourley, Catherine (2008), Gibson and Suffragists Girls. Perceptions of Women from 1900 to 1918, Mineápolis, Twenty-First Century Books.

Griswold, Robert L. (1980), "Apart but not Adrift: Wives, Divorce and Independence in California, 1850-1890", Pacific Historical Review, 49, (2), Oakland, University of California Press, pp. 265-283, doi: https://doi.org/10.2307/3638902

Hahn, Emily (1967), Romantic Rebels. An Informal History of Bohemianism in America, Boston, The Riverside Press Cambridge.

Hallet, Hillary A. (2011), "Based on True Story: New Western Women and the Birth of Hollywood", Pacific Historical Review, 80 (2), Oakland, University of California Press, pp. 177-210, doi: https://doi. org/10.1525/phr.2011.80.2.177

Hansen, Harry (1934), "The First Reader", The Pittsburgh Press, 18 de marzo, Pittsburgh, E.W. Scripps Company.

Hernández, Sonia (2021), For a Just and Better World. Engendering Anarchism in the Mexican Borderlands, 1900-1938, Champaign, University of Illinois Press.

Jensen, Joan M. y Ricci Lothrop, Gloria (1987), California Women: A History, San Francisco, Boyd \& Fraser Pub. Co.
Katz, Sherry (1991), "Dual Commitments: Feminism, socialism, and women's political activism in California, 1890-1920", tesis de doctorado en filosofía, University of California, Los Ángeles.

Komski, Elizabeth A. (2001), "Fashion's foes: Dress Reform from 1850-1900", tesis de maestría en artes, The College of William and Mary, Williamsburg, doi: https://dx.doi.org/doi:10.21220/s2-cmdg-dr92

Koven, Seth y Michel, Sonya (1993), Mothers of a New World. Maternalist Politics and the Origins of Welfare States, Londres, Routledge.

Lau Jaiven, Ana (2011), "Mujeres, feminismo y sufragio en los años veinte", en Gisela Espinosa Damián y Ana Lau Jaiven (coords.), Un fantasma recorre el siglo. Luchas feministas en México 1910-2010, Ciudad de México, Universidad Autónoma Metropolitana.

Levin, Joanna (2009), Bohemia in America 1858-1920, Stanford, Stanford University Press.

Lyons, Louis S. y Wilson, Josephine (1922), Who's who Among the Women of California, San Francisco-Los Ángeles, Security Publishing Company.

MacLeod, Kristen (2018), American Little Magazines of the Fin de Siècle. Art, Protest, and Cultural Transformation, Toronto, University of Toronto Press.

Mickenberg, Julia L. (2006), Learning from the Left: Children's Literature, the Cold War, and Radical Politics in the United States, Nueva York, Oxford University Press.

Narbona Carrión, María Dolores (2007), Sophie Treadwell. Contexto teatral, biografía, crítica y traducción de su obra Machinal, Málaga, Universidad de Málaga.

Newberry, Perry (1910), "Help for Carmel", The San Francisco Call, 22 de julio, San Francisco, Spreckels. 
OAC (Online Archive of California) (s.f.), "California Faces: Selections from the Bancroft Library Portrait Collection", Berkeley, University of California, <https://bit.ly/3CTMNz3>, 22 de noviembre de 2021.

Oikión Solano, Verónica (2018), Cuca García (1889-1973). Por las causas de las mujeres y la revolución, Ciudad de México, El Colegio de Michoacán/El Colegio de San Luis.

Orth, Michael (1969), "Ideality to Reality: The Founding of Carmel", California Historical Society Quarterly, 48 (3), Oakland, University of California Press, pp. 195-210, doi: https://doi. org/10.2307/25154365

Peaslee, Maude (1891), "The Pacific Coast Women's Press Association", The Pacific Rural Press, 4 de abril, San Francisco, <https://bit.ly/3xiDszX>, 22 de noviembre de 2021.

Porter, Susie (2020), Del ángel del hogar a oficinista. Identidad de clase media y conciencia femenina en México, 18901950, Ciudad de México, El Colegio de Michoacán.

Pratt, Mary Louis (2010), Ojos imperiales. Literatura de viajes y transculturación, Ciudad de México, Fondo de Cultura Económica.

Riegel, Robert E. (1963), “Women's Clothes and Women's Rights", American Quarterly, 15 (3), Baltimore, The Johns Hopkins University Press.

Robbins, Millie (1967), "Her Pen Made the Desert Bloom", San Francisco Chronicle, 28 de diciembre, San Francisco, Hearst Corporation.

Robertson, David Brian (2004), "The Progressive Era", en Daniel Béland, Christopher Howard y Kimberly J. Morgan (eds.), Oxford Handbook of U.S. Social Policy, Nueva York, Oxford University Press, doi: 10.1093/oxfordhb/9780199838509.013.009
Rocha Ismas, Martha Eva (2011), "Feminismo y revolución", en Gisela Espinosa Damián y Ana Lau Jaiven (coords.), Un fantasma recorre el siglo. Luchas feministas en México 1910-2010, Ciudad de México, Universidad Autónoma Metropolitana.

Ross, Ishbel (1936), Ladies of the Press. The Story of Women in Journalism by an Insider, Nueva York, Harper \& Brothers Publishers.

Schweizer, Valerie (2020), "Divorce: More than a Century of Change, 1900-2018", Washington, D.C., National Center for Family \& Marriage Reasearch-Bowling Green State University, <https://bit.ly/ $3 C P S \vee \times Q>, 10$ de noviembre de 2021.

Sewell, Jessica Ellen (2011), Women and the Everyday City, Public Space in San Francisco, 1890-1915, Mineápolis, University of Minnesota Press.

Shaffer, Ronald (1976), "The Problem of Consciousness in the Woman Suffrage Movement: A California Perspective", Pacific Historical Review, 45 (4), Oakland, University of California Press, pp. 469-493.

Shaw Peterson, Joyce (1993), "Matilda Robbins: A woman's life in the labor movement, 1900-1920", Labor History, 34 (1), Londres, Taylor \& Francis, pp. 33-56, doi: 10.1080/00236569300890021

Shoaf, George H. (1911), "Magon is Arrested", Appeal to Reason, 24 de junio de 1911, Kansas, Girard.

Showalter, Elaine (2009), A Jury of Her Peers. Celebrating American Women Writers from Anne Bradstreet to Annie Proulx, Nueva York, Virago.

Smith, Sidonie (2001), Moving Lives. Twentieth Century Women's Travel Writing, Mineápolis, University of Minnesota Press.

Tuñón Pablos, Esperanza (2011), “El Frente Único Pro Derechos de la Mujer durante el Cardenismo", en Gisela Espinosa Damián y Ana Lau Jaiven (coords.), Un 
fantasma recorre el siglo. Luchas feministas en México 1910-2010, Ciudad de México, Universidad Autónoma Metropolitana.

Turner, L. Lucile (1924a), "Songs of the Dakotas", The Wanderer, marzo, San Francisco, s/e.

Turner, L. Lucile (1924b), "Songs of the Dakotas II", The Wanderer, agosto, San Francisco, s/e.

University of California (1903), Register 1902-1903, Berkeley, University of California Press.

University of California (1898), Register 18971898, Berkeley, University of California Press.

Valles Ruiz, Rosa María (2010), Sol de libertad. Hermila Galindo: feminista, constitucionalista y primera censora legislativa en México, Ciudad de México, Universidad Autónoma del Estado de Hidalgo.

Vasquez Montaño, Rosario Margarita (2019), "Ethel Duffy Turner. Una biografía política e intelectual desde la frontera. 1885-1969", tesis de doctorado en historia, El Colegio de México, Ciudad de México.

Walsh, Patrick John (2001), "Boosting Bohemia: Counterculture, Development, and Identity in the American West, 19001990", tesis de doctorado en filosofía, The University of Texas, Austin.

Weinbaum, Alys Eve; Lynn M., Thomas; Ramamurthy, Priti; Poiger, Uta G.; Yue Dong, Madeleine y Barlow, Tani (2008), The Modern Girl Around the World. Consumption, Modernity and Globalization, Durham, Duke University Press.

Weinstein, Dave (2008), It Came from Berkeley. How Berkeley Changed the World, Utah, Gibbs Smith.

Willey Todd, Ellen (1993), The "New Woman" Revisited. Painting and Gender politics on Fourteenth Street, Berkeley, University of California Press.
Wood, Inga (1909), "A Church in the Desert", The Border, enero, s/e.

Yamane, Nan Towle (2000), "Pacific Coast Women's Press Association, 1890-1999", en Elizabeth V. Burt (ed.), Women's Press Organizations, 1881-1999, Westport, Greenwood Press, pp. 189-198.

Recibido: 24 de noviembre de 2021. Aceptado: 16 de diciembre de 2021. Publicado: 12 de enero de 2022.

\section{Rosario Margarita Vasquez Montaño}

Es doctora en historia por El Colegio de México. Actualmente es investigadora adscrita al seminario académico de Historia Contemporánea en El Colegio Mexiquense, A.C. Es miembro del Comité Directivo de la Red de Estudios de Historia de las Mujeres y de Género en México (REDMUGEN). Su línea de investigación está enfocada en la historia sociopolítica de las mujeres, siglo $X X$, en particular la presencia extranjera en México. Entre sus más recientes publicaciones destacan, como autora: "Los Turner en México: una mirada a las postrimerías del porfiriato", en José Enrique Covarrubias e Itzel Toledo (coords.), Viajeros en el México porfiriano (1876-1911), Ciudad de México, UNAM (próximamente); "El retorno magonista. Resistencia y adaptación al México de la posrevolución, 1920-1950”, en Saúl I. Hernández y Fernando Saúl Alanís (coords.), La migración del retoro en México, una perspectiva histórica, San Luis Potosí, El Colegio de San Luis Potosí (próximamente); "Organización obrera y políticas laborales en las minas de cobre de México y Chile, (1900-1940)", Región y sociedad, vol. 31, Hermosillo, El Colegio de Sonora, e1040 (2019); "Bienes intervenidos. La doble cara de la legitimidad revolucionaria (1913-1920)", en Dora Elvia Enríquez Licón y Juan Manuel Romero Gil (coords.), Sonora: frontera, sociedad y medio ambiente. Siglos XIX y XX, Hermosillo, Universidad de Sonora, pp. 257-278 (2018). 